\title{
Pulmonary artery coming from patent ductus arteriosus
}

INSERM

\section{Source}

INSERM. (1999). Orphanet: an online rare disease and orphan drug data base. Pulmonary artery coming from patent ductus arteriosus. ORPHA:99049

Pulmonary artery coming from patent ductus arteriosus is a rare, congenital, nonsyndromic heart malformation characterized by the presence of a single (or a double) patent ductus arteriosus which associates one or both pulmonary arteries originating from it. Manifestations are variable, frequently presenting with neonatal cyanosis, severe progressive hypoxia, persistent pulmonary hypertension, increased susceptibility to pulmonary infections, and thoracic asymmetry resulting from asymmetric lung volumes. 